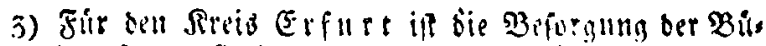

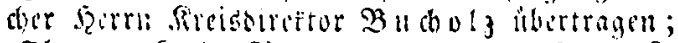

4) Firr ton firch ?o

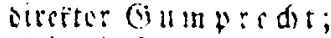

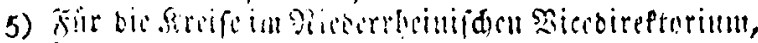

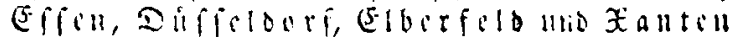

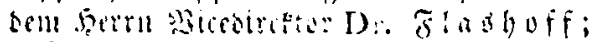

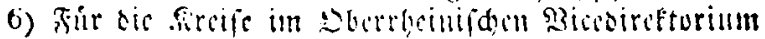

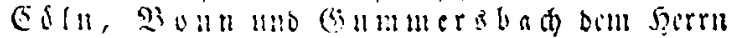

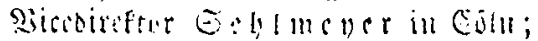

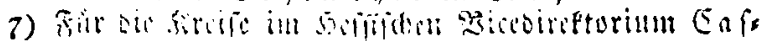

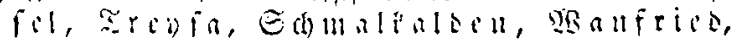

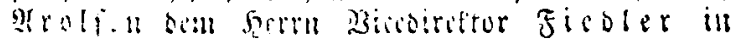
(intil

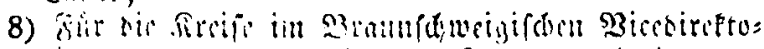

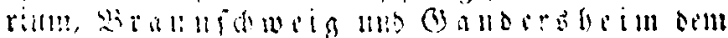

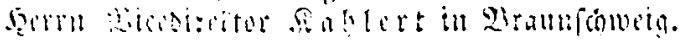

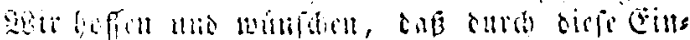

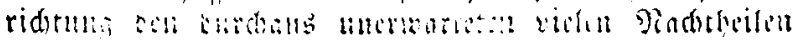

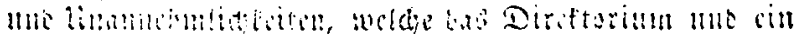

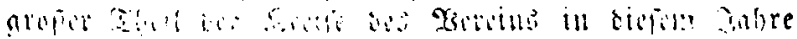

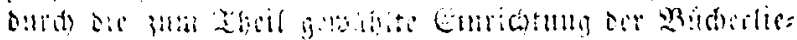

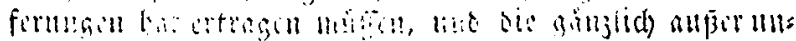

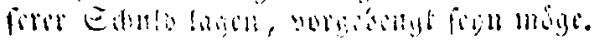

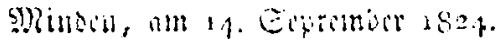

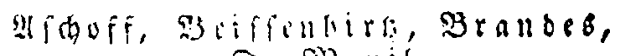
D॥ Ninil.

\title{
4. 2Tuforterurg.
}

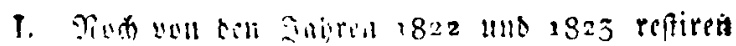

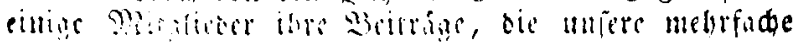

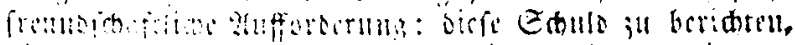

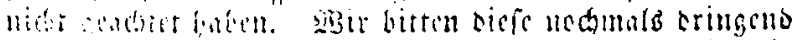

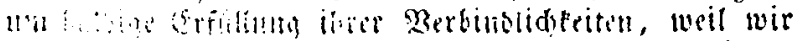

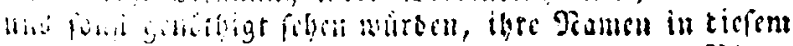




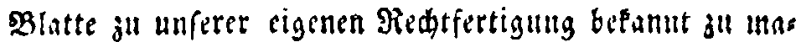
went.

II. Diejenigen Mitglieder, Ioelde von diejem Inth= re (182.t) ibre Beitráge nod nidst elllgejand baben, wer= ben biflidit gebetell, felbige oell Gerra Freisoireftoren

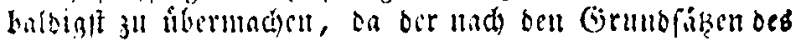
Berins felfigeferte Termin betamntlid lángft abgelau: fen ilt.

Miuba, sen 14. Eiptember 182.

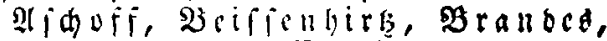
Du $)$ c uil.

5. Befanntmadumg an rie șern Plitglieber beo Sireipe Edimaltalben.

Da Scr ferr Rlpotbefor Barubagen in Sdmals

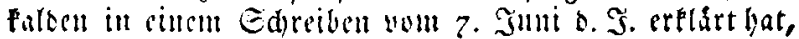

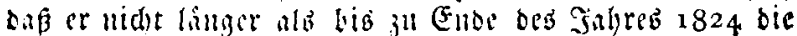

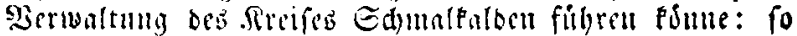

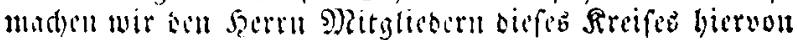

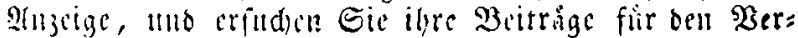

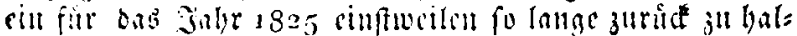

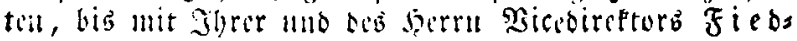

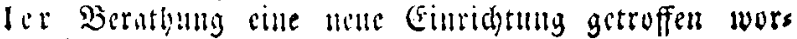
bin itit.

9)illow, am 14. Eiptcuber 1824 . Af d) off, seiffenbirg,

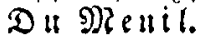

\section{Die Berwaltming oco Sircifỏ Clcve uno Xans ten betreffent.}

Die Berwaltung ses gemannten Rreifeb, welde bibs

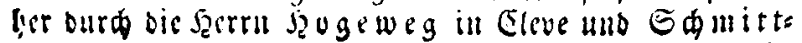

